\title{
Economic Analysis of the Potential of Cellulosic Biomass Available in France from Agricultural Residue and Energy Crops
}

\author{
Delphine Simon • Wallace E. Tyner • Florence Jacquet
}

Published online: 19 November 2009

(C) Springer Science + Business Media, LLC. 2009

\begin{abstract}
The objective of this research is to evaluate the feasibility and locations of using cellulosic biomass both from crop residues and from dedicated energy crops to supply 200-million-liter-biodiesel plants in France. The estimation of the potential amount of agricultural residue available in 2015 in each region of France is calculated. The residues considered in this study come from cereal straw and corn stover. Results show that eight out of the twenty one French regions have enough agricultural residues available to supply at least one 200 million liter biofuel plant. Region Centre has the largest potential, with enough residues to supply three to five plants. Finally, cost of supplying one biodiesel plant of 200 million liters in the region Centre is estimated. Results show that collection of biomass will be effective in an area with a radius of $58 \mathrm{Km}$ to $168 \mathrm{Km}$ depending of the raw material considered and its abundance. The cost of supplying a plant with miscanthus is much higher than with residues only. Thus, crop residues appear to offer a lower cost to produce biodiesel in the near term compared to a dedicated crop. Results show that production of biofuel from cellulosic biomass should not be limited by the supply of raw material, but costs of conversion to liquid fuels clearly will play a key role in the
\end{abstract}

\section{Simon}

Purdue University,

West Lafayette, IN, USA

W. E. Tyner $(\bowtie)$

Department of Agricultural Economics, Purdue University,

West Lafayette, IN 47907, USA

e-mail: wtyner@purdue.edu

F. Jacquet

French National Institute of Agronomic Research (INRA),

Paris, France development of cellulosic biofuels. Energy prices and policies will have a significant impact on second generation biofuel development.

Keywords Agricultural residues · Cellulose - Biomass · Miscanthus · Biodiesel $\cdot$ Land-use $\cdot$ French biofuels potential

\section{Introduction}

France, like many others countries, is seeking to increase the share of its domestic energy supplies. Even if its largest domestic energy production is nuclear $(40 \%$ of the total primary energy production), $33 \%$ of its energy supply is foreign oil [14]. Reducing reliance on foreign oil is largely due to recent concerns over the availability of petroleum supplies and greater concerns of the fossil fuel environmental consequences. With $97 \%$ of its road transportation depending on oil imports, France is highly vulnerable and is subject to the high volatility of petroleum prices [37]. Liquid biofuels are considered by many as one of the best options to replace petroleum in transport. They are currently available as substitutes for traditional fuel, and they are environmentally friendly [3]. Moreover, transportation carbon dioxide $\left(\mathrm{CO}_{2}\right)$ emissions are the largest cause of $\mathrm{CO}_{2}$ emissions in France with $26 \%$ of the total [37]. The environmental impact of biofuels is also an important factor that led to their production in Europe. Developing and using biofuels represents an opportunity to reduce greenhouse gas (GHG) emissions in accordance with Kyoto protocol commitments [22]. France as part of the European Union agreed to reduce its GHG emissions by $8 \%$ below 1990 levels by the period 2008-2012 [14]. Also, GHG emission saving due to the use of biofuels instead of petroleum is expected to reach $50 \%$ by 2017 [8]. 
Based on the biofuels directive (2003/30/EC), France established a target of $5.75 \%$ biofuel in transportation fuels by 2008 ( 2 years earlier than required by the EU biofuel directive), $7 \%$ by 2010 , and $10 \%$ by 2015 [19, 20]. France is one of the main biodiesel producers in Europe, and its production represents $14 \%$ of the world biodiesel production [11]. Biodiesel is blended with diesel which represented $73 \%$ of total liquid fuel consumption in France [25]. It is currently based on vegetable oil produced from rapeseed oil, (which represents $87 \%$ of total biofuels production in France), and from sunflower (7\%). Ethanol is produced from wheat and sugar beet (each 3\% of biofuel production) and blended with gasoline [19, 20]. French ethanol production represents $2 \%$ of the world production [40]. In order to meet the Directive, either more land will have to be devoted to produce additional energy production, crop residues will be required, or France will need to import biofuels [47]. Moreover importing biofuels will not decrease energy dependence, and a large amount of arable land cannot be moved from food production to biofuel production without endangering the food independency. Thus, a diversification of biofuel sources is necessary. Cellulosic biomass, also called second generation biofuel, is a potentially attractive energy feedstock. Cellulose is a polymer of glucose and xylose produced by every living plant [35]. Consequently, cellulosic biomass includes all plants and plant-derived materials. It is found abundantly in forest (i.e. logging residues, processing mill residues, urban wood residues) and in agricultural resources (i.e. crop residues, grains, perennial grasses, animal manures, food/ feed processing residues) [38]. One advantage of residue use is the synergy between energy production and food material production [23]. Crop residues represent the nonedible plant parts which are left in the field after harvest [31]. All crop residues cannot be utilized for energy production due to the small amount of residues produced by some species (potatoes, sugar beet). Sugar beet residues, for example, are difficult and expensive to collect. Straw from cereal crops and stalks from corn and sorghum are the main source of residues that can be removed [13, 29, 31]. In addition to crop residues, dedicated energy crops provide another potential feedstock, and we will also examine that resource using miscanthus. In both cases, this analysis assumes that EU directives in place to produce liquid fuels from renewable sources will be maintained. We are not arguing that it is economically efficient from a pure market cost perspective to produce cellulosic biofuels.

The first objective of this study is to determine how much cellulosic raw material would be regionally available in France for possible conversion to biofuel from traditional crop residues. Given the crops produced in France we will focus our study on cereal straw from wheat, barley, oats and rye and corn stalks. The assessment of the geographical distribution of these residue crops is important in evaluating the feasibility of biofuel plant location.

The second objective is to estimate the cost of supplying a plant of 200 million liters of biodiesel from crop residues and dedicated energy crops in France in the region with the highest potential supply. Current corn ethanol plants in the U.S. are about 400 million liters, but we assume the cellulose plants will be smaller to reduce collection cost and radius. We assume that a thermochemical conversion process (either gasification or pyrolysis) would be used to produce hydrocarbons directly from biomass. In reality, it likely would be a mixture of bio-diesel, bio-gasoline, and other outputs. However, given the higher demand in France for diesel fuels, the process likely would be tuned to produce a greater proportion of diesel.

\section{Methods}

To estimate the future supply of agricultural residues in 2015 , estimation of future crop production is needed. A micro-economic supply chain model developed by the French National Institute of Agronomic Research (INRA) was used. It is a linear programming tool named OSCAR (Optimisation du Surplus économique des Carburants Agricoles Renouvelables) initially developed to evaluate public policy regarding development of biofuels in France in the 90s. If all we needed was an estimate of residue potential, we could have used the crop mix by region in recent years. However, our analysis extends out over several years, and relative crop prices (from OECD/FAO) change over time leading to changes in crop mix. Also, when we introduce the new dedicated energy crop, miscanthus, we need to determine the impact of that crop on production of other crops.

The OSCAR model is a partial equilibrium model built to illustrate the agro-energy chain structure in France by simulating farmers' behaviour. It is written in General Algebraic Modeling System (GAMS) and integrates a sequential multi-annual and regional agricultural sector [41]. The objective function of the model is to maximize the net income of the farmers. The regional agricultural sector model maximizes total gross margin by determining farmers' decisions. Crop prices are set exogenously, and the model determines crop production [2]. It considers that farmers maximize their individual gross margin by cultivating the most profitable set of crops subject to crop prices, agronomic, and institutional constraints [42, 46]. The main assumptions of the model are that farmers are considered to be "price takers", the agro sector is closed to imports, and crop demands are considered to be totally elastic [3]. These assumptions would still be valid in a regime with more biofuels production, although plants and 
farmers likely would use long term production contracts to reduce risk on both sides. The model optimizes incomes of the sector for several years based on exogenous variables.

Figure 1 provides a flow chart for the OSCAR model.

\section{Data Sources}

The model is based on a sample of 1,094 farms from the 2004 data of the Farm Accountancy Data Network (FADN). The FADN collects every year micro-economic data from national surveys in each country of the European Union. The survey covers only the agricultural holdings which could be considered commercial with regards to their size [15]. The sample comes from OTEX 13 and 14 of FADN which represent farms specialized in arable crops. They have an average size of 142 ha. The sample of 1,094 farms in OSCAR represents 84,429 farms specialized in crop production in France [19, 20].

The data used for the crop prices come from the FAOOECD (Food and Agriculture Organization-Organization for Economic Co-operation and Development) projections on prices for wheat, corn and oilseed (soybean). The prices of other crops are indexed on the historical ratios over the past 10 years of each other crop to these three prices. The prices used for the analysis are contained in Table 1.

To obtain realistic crop production, different agronomic constraints are established in the model. They are derived from observation of maximum area in the model or from INRA expert opinion. Some agronomic constraints represent the maximum percentage of each farm's arable land

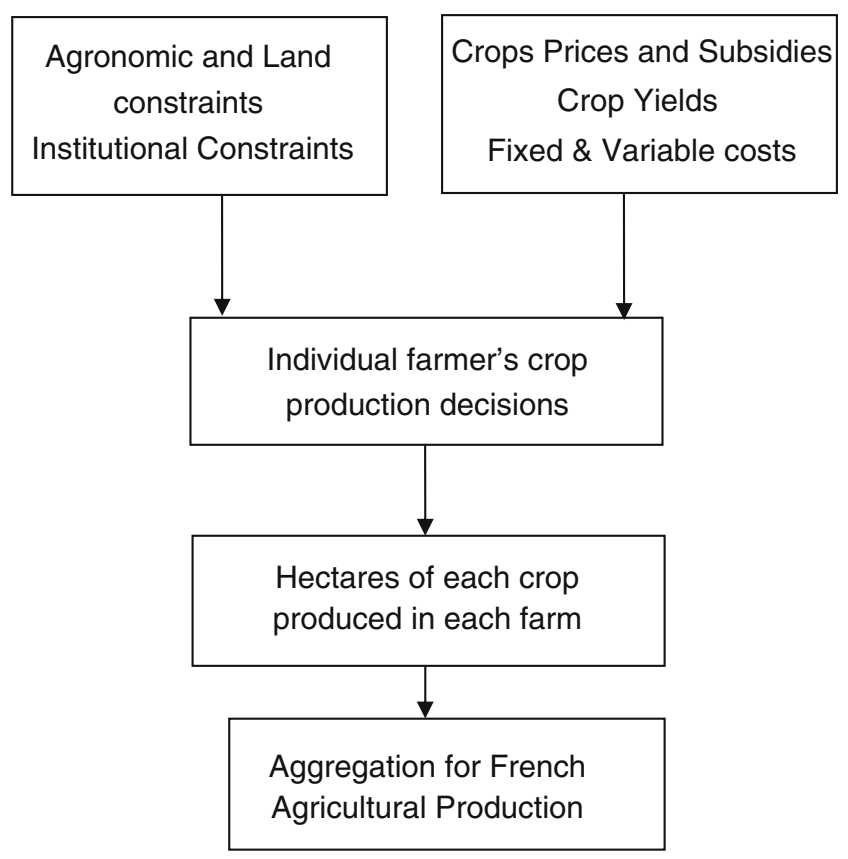

Fig. 1 OSCAR model
Table 1 Agricultural commodity prices

\begin{tabular}{lrrrrrrr}
\hline$€ / \mathrm{q}$ & 2009 & 2010 & 2011 & 2012 & 2013 & 2014 & 2015 \\
\hline Wheat & 14.4 & 14.2 & 13.8 & 13.7 & 13.7 & 13.5 & 13.4 \\
Corn & 11.5 & 10.9 & 10.6 & 10.7 & 10.4 & 10.2 & 10.3 \\
Soybean & 22.8 & 22.7 & 22.3 & 22.0 & 22.0 & 21.9 & 21.8 \\
Barley & 14.6 & 14.3 & 13.9 & 13.8 & 13.8 & 13.7 & 13.6 \\
Oats & 12.8 & 12.6 & 12.3 & 12.2 & 12.2 & 12.1 & 12.0 \\
Rye & 14.0 & 13.8 & 13.4 & 13.3 & 13.2 & 13.1 & 13.0 \\
Triticale & 13.0 & 12.8 & 12.4 & 12.3 & 12.3 & 12.2 & 12.1 \\
Sorghum & 8.6 & 8.2 & 8.0 & 8.0 & 7.8 & 7.7 & 7.7 \\
\hline
\end{tabular}

Source: OECD-FAO 2007 and authors' calculations.

that can produce a specific crop. For example, rapeseed production cannot exceed $40 \%$ of the farm total arable land and sunflower $30 \%$. Peas, horse bean and sugar beets cannot be produced on more than respectively $15 \%$ and $30 \%$ of farm total area. Some constraints are applied with respect to wheat production of the previous year, which varies for each farm. The area planted to wheat must be at least $70 \%$ of the area planted to wheat the previous year. These constraints introduce reality from the field that would not necessarily emerge from a completely unconstrained linear programming model.

For subsidies, according to Common Agricultural Policy CAP 2006 we assumed the decoupled subsidy represents $75 \%$ of the total subsidies (which means that $75 \%$ of the total subsidies are not linked to production). A subsidy of 45 Euros per hectare and per year has been applied for areas under energy crops. The set-aside land is not mandatory in 2008, and it is not expected to be used again. According to Agreste [1] an agricultural statistics organization, an average set aside of $3.5 \%$ should be considered in each farm as the all land cannot always be used. It represents the marginal land which is usually not cultivated due to bad soil or difficulty of access, so uncultivated land is assumed to be at least $3.5 \%$ from 2008 to 2015 .

\section{Residue to Product Ratio}

Crop residues represent the non-edible plant parts which are left in the field after harvest [31]. Residues represent a low cost biomass supply available in the near term [44]. All crop residues cannot be utilized for energy production due to the small amount of residues produced by some species (potatoes, sugar beet). Straw from cereal crops such as wheat, barley, oats, rye, rice and stalks from corn and sorghum are the main sources of residues that can be removed [13, 29, 31]. The availability of residues is not directly measured, but it is evaluated on the basis of the area used to produce these crops, on crop yields, on the estimation of the residue to product ratio RPR (ratio 
between the yields of residue and product) and on the removal rate [17, 23]. Koopmans and Koppejan [30] did an overview of the residue to product ratio (RPR) data from available studies between 1984 and 1993 and found large variations. Most of the studies focused on EU or the US in the last decade consider that the residue to production ratios range between 0.5 to 2 for cereal straw from wheat, barley, oats and rye and between 0.7 to 1.3 for corn stalks. Table 2 presents the residue to product ratios used in this study. Sensitivity analysis is done by assuming three different removal rates. Total residue availability is a function of both the RPR and the removal rate, so doing the analysis under a wide range of removal rates effectively covers sensitivity on both factors.

To illustrate the calculation, wheat yield is assumed to be $7.5 \mathrm{t} / \mathrm{ha}$ and corn yield $9.9 \mathrm{t} / \mathrm{ha}$. Thus the available wheat straw would be $9 \mathrm{t} / \mathrm{ha}$ and corn stover $9.9 \mathrm{t} / \mathrm{ha}$. Applying the low limit of residue availability of $25 \%$ (see discussion below), the available residue for wheat and corn would be $2.25 \mathrm{t} / \mathrm{ha}$ and $2.48 \mathrm{t} / \mathrm{ha}$ respectively.

The total amount of residues left in the field cannot be harvested due to machinery capacity and the need to prevent soil erosion and maintain carbon levels [38]. The quantity that is actually removed depends on the removal rate.

\section{Removal Rate}

The removal rate refers to the percentage of available residues that can be collected without increasing soil erosion or diminishing soil fertility. It is hard to assess the amount of residue that can be removed as it depends on grain yields [36] which depends on local conditions: weather, crop rotation, existing soil fertility, tillage practices and slope of the land and on the time frame of the study $[16,29]$. Most studies examining global biomass supply assumed that about $25 \%$ of the total available agricultural residues can be removed [13, 23]. Studies focused on the US, Europe, and France assumed a removal rate which mainly ranges between 20 and $40 \%$. However, some studies focus on specific parts of France found higher results. Institut National de Recherche Agronomique (INRA) and Arvalis (technical institute in charge of applied research on agriculture) looked at agricultural practices in the French region Picardie and found that a removal rate of 33\% seems to only decrease the organic matter by $2.5 \%$ in 50 years [39]. The projected average removal rate in the six main

Table 2 Residue to product ratio used in this analysis

\begin{tabular}{lllll}
\hline Wheat & Barley & Oats & Rye & Corn \\
\hline 1.2 & 1 & 1.2 & 1 & 1 \\
\hline
\end{tabular}

cereals areas in France is estimated at 38.5\% [17]. Another study suggested an average removal rate of $53 \%$ and expected that the proportion of straw removable can go up to 50 to $60 \%$ under certain conditions [45]. However these high rates can be usually linked with particular tillage practices (good fertilization due to inputs of manure in livestock regions or good soil).

This literature review shows that there are a wide range of removal rates used in previous studies. Consequently, in order to capture this variation, analysis is done for three removal rates. First, a conservative removal rate of $25 \%$, then $35 \%$ which corresponds to a removal rate frequently used in the literature, and finally, $55 \%$, which is a higher value but one possible in some regions of France as described below.

\section{Miscanthus}

Miscanthus has been identified as one of the best choices for low input bioenergy production in Europe and USA [28]. Recent studies on energy crops found that miscanthus possesses most of the characteristics required for the "ideal energy crop" [21]. The crop miscanthus is not currently widely cultivated, but some trials have been done, mainly in Europe in recent decades. These trials tend to confirm the results that have been reported in the literature. Thanks to its efficient recycling system, miscanthus needs fewer inputs than other potential energy crops (reed canary grass, triticale and switchgrass) for a high production of biomass $[28,33]$. Its high cellulosic fraction $(43 \%)$ makes it suitable for second generation biofuel [4]. Miscanthus is a perennial rhizomatous C4 grass originated from East Asia. It was first introduced in Europe in 1935 and has been the subject of studies as an energy crop since the 80 's [43]. There are different species of miscanthus; the favourite in mid-Europe is Miscanthus Giganteus a vigorous sterile clone. It is the most productive of all the genotypes tested [7]. Miscanthus is planted in spring, and the first year is not harvested. The optimum production is reached in 3-5 years. The optimal cultivation period is still being investigated, but it is at least 10 years, normally $16-18$ years, possibly as long as 25 years [4]. Because miscanthus not widely produced, little definitive data exists on it. Some of the trials published to date are summarized in Table 3.

Potential miscanthus yield has been estimated for each region. Yields vary with the age of crop, planting density, environmental factors (soil, local climate) and agronomics practiced [33, 49]. According to several trials in Europe, after the two first years of production miscanthus yield ranges between 10 and $30 \mathrm{t} \mathrm{DM} \mathrm{ha}^{-1}$. This is consistent with a French study which concludes that miscanthus has a potential of 20 to $30 \mathrm{t} \mathrm{DM} \mathrm{ha}^{-1}$ in the French regions with oceanic influence after 2-3 years of establishment [48]. 
Table 3 Miscanthus yields reported in the literature

\begin{tabular}{lll}
\hline Study & Site & Yield in t (DM)/ha (year 3 onwards) \\
\hline Clifton Brown et al. [7] & Various site in Europe & 22.7 \\
Heaton et al. [21] & Various site in Europe & 10.78 \\
Lewandoski et al. [33] & Various site in Europe & $10-25$ \\
Bullard [6] & Various site in Europe & $12-24$ \\
Marsac [34] & Various site in Europe & $10-20$ \\
Huisman et al. [24] & Netherlands & 12 \\
DEFRA [9] & England & $11-15$ \\
BICAL Biomasse France [4] & France & $15-25$ (average 17) \\
Warnant [49] & France & $12-16$ (average 13) \\
GIE Arvalis/Onidol [18] & France & $10-20$ (average 14) \\
EC-BREC [12] & France & $25-8$ (average 16) \\
\hline
\end{tabular}

Miscanthus' yields are mainly correlated to weather variation (rainfall and temperature) between different areas [27]. To estimate the potential yield of miscanthus in this model, we used a linear regression based on USA trial data and applied it to French data. The regression was estimated by Dr. Ivanic from Mendel Biotechnology. Miscanthus yields are correlated to temperature through the growing degree days (GDD) and precipitation. Weather data was obtained from the website meteociel.com, which gives the daily maximum and minimum temperature and precipitation for various locations from 2003 to present.

Miscanthus peak Yield $=6.91+0.0416$ precipitation $*$ GDD $/ 1000$

\section{[27]}

Miscanthus yield is in short tons per acre, precipitation is in inches per year and GDD is in degree Fahrenheit per year. Historical precipitation and temperature data for each region in France were used to get an estimation of the yield of miscanthus in each region for 4 years (from 2003 to 2008). The results show a small variability over the years in each region. The average yield was estimated for each region based on the results obtained for the 4 years and ranged from 16 to $21 \mathrm{t} /$ ha depending on the region. The yield by region, miscanthus price, and the cost per hectare were input into the crop optimization model (OSCAR) to determine production in each region as a function of the competitiveness of miscanthus versus the other crops.

\section{Transformation of the Biomass into Biodiesel}

Second generation biofuels using a thermochemical conversion process involve the gasification of biomass and the further transformation of the gas into a syngas before being converted into a liquid fuel. In this study the use of the Fisher-Tropsch (FT) synthesis process is assumed with an efficiency of 46 percent. This number comes from the estimation of Wright and Brown [50]. The liters/ton of the feedstuff into biodiesel varies depending on the source of biomass used. In this study, based on the energy content of each feedstock and 46\% conversion efficiency, we calculate a conversion rate of 187 liters of biodiesel per metric ton for cereal straw, 203 liters of biodiesel per metric ton for corn stalks, and 183 liters of biodiesel per metric ton for miscanthus (author's calculations).

\section{Assumptions on Production and Transportation Cost}

In order to assess the cost of supplying a 200 million liter cellulosic plant from agricultural residue and/or energy crop we assumed average cost of production and transportation. The cost of production of straw has been assessed at $85 € / \mathrm{t}$ DM and miscanthus at about $90 € / \mathrm{t}$ DM by the French research Institute Arvalis [32]. Corn stover production cost has been estimated at $42 € / \mathrm{t} \mathrm{DM}$ and transportation cost at $0.18 €$ per kilometer per ton (adjusted from [5] estimation for the US). The corn residue production cost includes collection, baling, wrapping, nutrient replacement, and storage until needed by the plant. Details are covered in Brechbill [5].

\section{Results}

The first set of results are for residues alone and show that under the three scenarios with different removal rates $(25 \%$, $35 \%$ and $55 \%$ ) some regions met the target of 200 million liters of biofuel production or more. Then in the second set of results we add miscanthus for the most productive region, region Centre.

Three regions met the target of an economical plant size of 200 million liters of biodiesel using only residue under the scenario with the low removal rate of $25 \%$ (Scenario 1 ). Five regions met the target under the scenario with the middle removal rate of $35 \%$ (Scenario 2), and nine regions 
Table 4 Biodiesel production for each region using residue only at three removal rates

\begin{tabular}{|c|c|c|c|}
\hline \multirow[t]{2}{*}{ Regions } & \multicolumn{3}{|c|}{$\begin{array}{l}\text { Biodiesel potential production } \\
\text { (millions of liters) }\end{array}$} \\
\hline & $\begin{array}{l}\text { Scenario } 1 \\
(25 \%)\end{array}$ & $\begin{array}{l}\text { Scenario } 2 \\
(35 \%)\end{array}$ & $\begin{array}{l}\text { Scenario } 3 \\
(55 \%)\end{array}$ \\
\hline Centre & 367 & 514 & 808 \\
\hline Champagne & 246 & 344 & 541 \\
\hline Picardie & 239 & 335 & 527 \\
\hline Poitou & 161 & 225 & 354 \\
\hline Aquitaine & 170 & 239 & 375 \\
\hline Midi-Pyrénées & 125 & 175 & 274 \\
\hline Bourgogne & 142 & 198 & 312 \\
\hline Ile De France & 129 & 180 & 283 \\
\hline Nord & 96 & 134 & 211 \\
\hline Haute Normandie & 78 & 109 & 171 \\
\hline Lorraine & 62 & 86 & 136 \\
\hline Pays de la Loire & 67 & 94 & 148 \\
\hline Alsace & 71 & 99 & 156 \\
\hline Rhone Alpes & 40 & 56 & 89 \\
\hline Basse Normandie & 40 & 56 & 88 \\
\hline Auvergne & 33 & 47 & 74 \\
\hline Franche Comté & 19 & 27 & 42 \\
\hline Languedoc Roussillon & 10 & 14 & 23 \\
\hline Provence Alpes Cote d'Azur & 8 & 12 & 18 \\
\hline Bretagne & 10 & 14 & 22 \\
\hline Limousin & 1 & 1 & 2 \\
\hline
\end{tabular}

with the highest removal rate of $55 \%$ (scenario 3 ). Table 4 shows a summary of the results for the three scenarios.

Under the first scenario with a removal rate of $25 \%$, Region Centre, Champagne and Picardie met the targeted amount (200 million liters). Region Centre has the highest potential production with 367 million liters. As shown in Fig. 2, these three regions are located in the northern France. Region Centre's cereal production represents 13.4\% of the national production. Champagne-Ardenne's and Picardie's cereal production represent $8.5 \%$ and $8.6 \%$ of the total production in 2007 [26].

Figure 3 shows the results for the second scenario with a higher removal rate of $35 \%$. Region Centre still has the highest estimated production of 514 million liters per year which is more than two times the targeted amount of 200 million liters. Meanwhile, regions Champagne and Picardie produced around 300 million liters per year. Two more regions, Poitou and Aquitaine, just reached the threshold of 200 million liters production with 225 million and 239 million liters per year respectively. All these regions have common borders with another region that meets the target which could facilitate the collection of the biomass supply for the closest plant. The rest of the regions produced less than the target amount.

Under scenario three with a removal rate of $55 \%$, nine out of 21 regions had an estimated production higher than 200 million liters as presented in Fig. 4. More than one plant of 200 million liters could be potentially built in three regions (Centre, Champagne and Picardie). If it considered that more than one plant of 200 million liters could be built
Fig. 2 Geographic representation of estimated biodiesel production for scenario 1

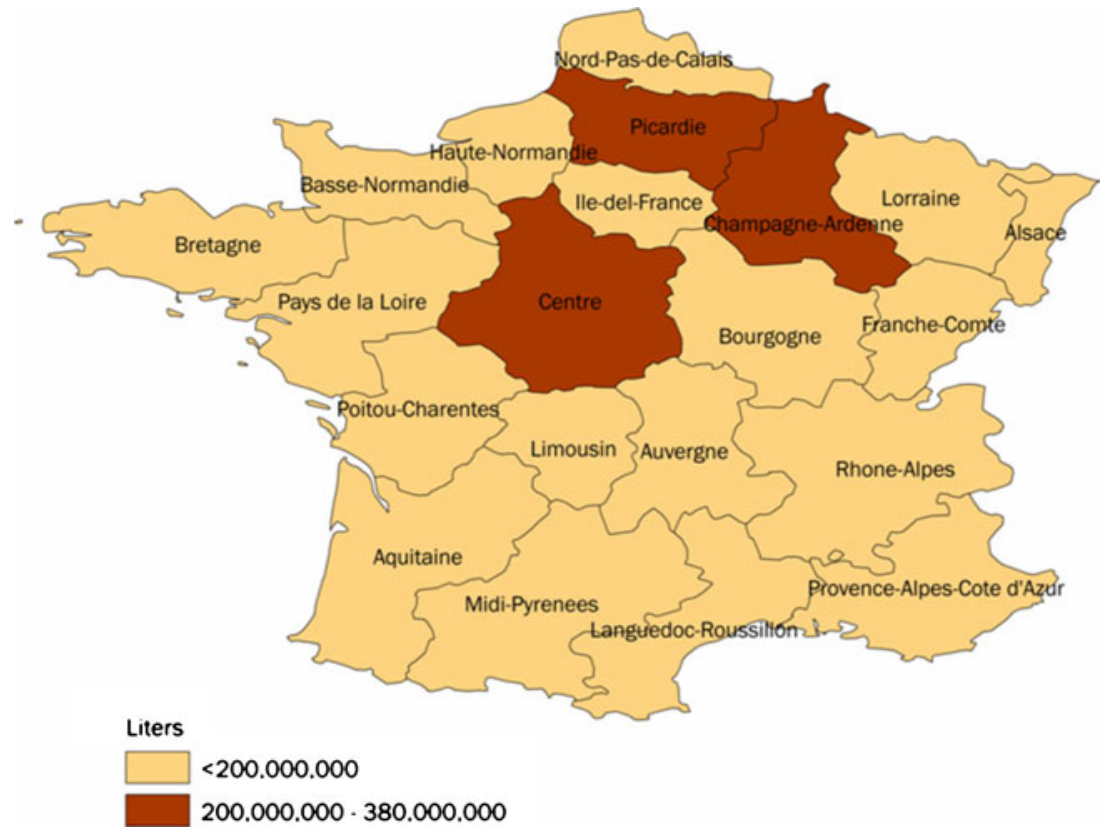


Fig. 3 Geographic representation of estimated biodiesel production with a removal rate of $35 \%$

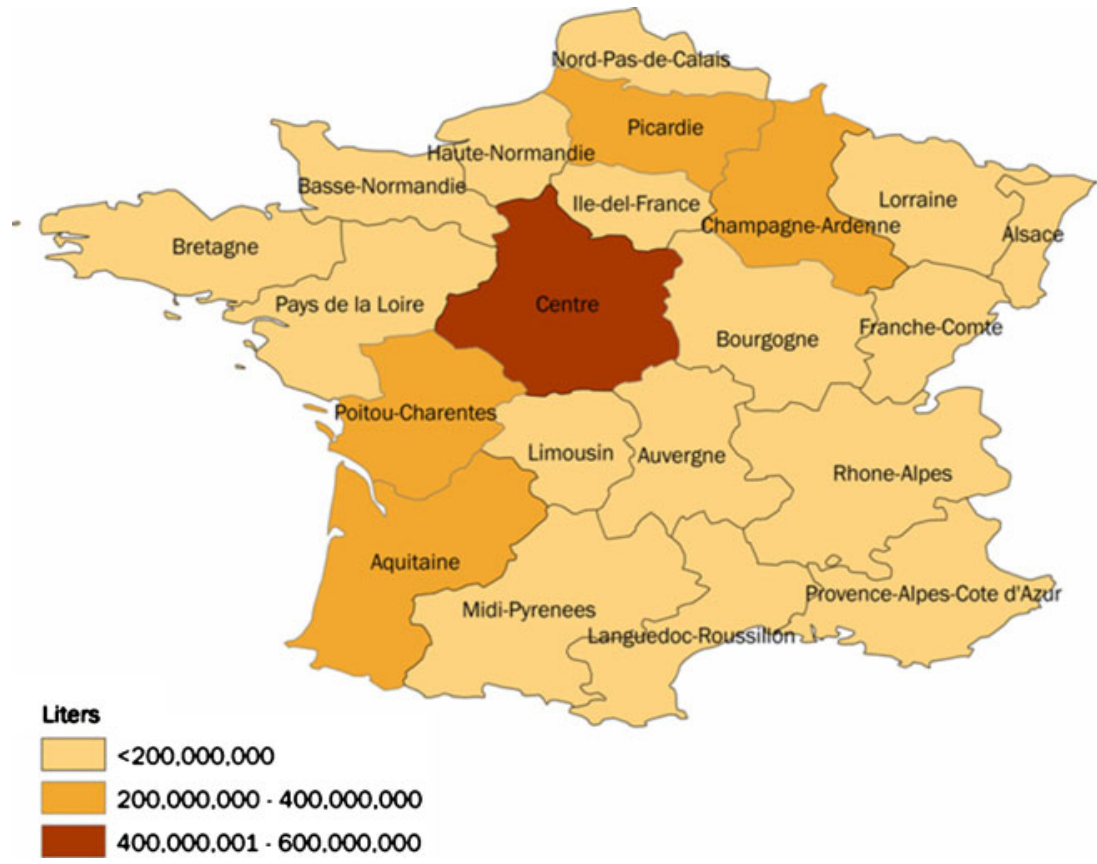

in one region, the total estimated production for these eight regions would be 2.8 billion liters. This represents $67 \%$ of the biodiesel production target for 2015 [10].

In summary, France has a potential to produce biodiesel from agricultural residues. Under the different scenarios, three to nine regions could produce more than 200 million liters of biodiesel. In regions Centre, Champagne and Picardie more than one plant potentially could be built.
Estimation of the Cost of Supplying One Cellulosic Plant in Region Centre Including Miscanthus

We limited the cost study to the region with the highest potential, region Centre. Cost of transportation varies with respect to the distance between the biomass and the plant. We assumed that the plant is located in the center of the region in Romorantin-Lantenay. The marginal transportation
Fig. 4 Geographic representation of estimated biodiesel production for scenario 3

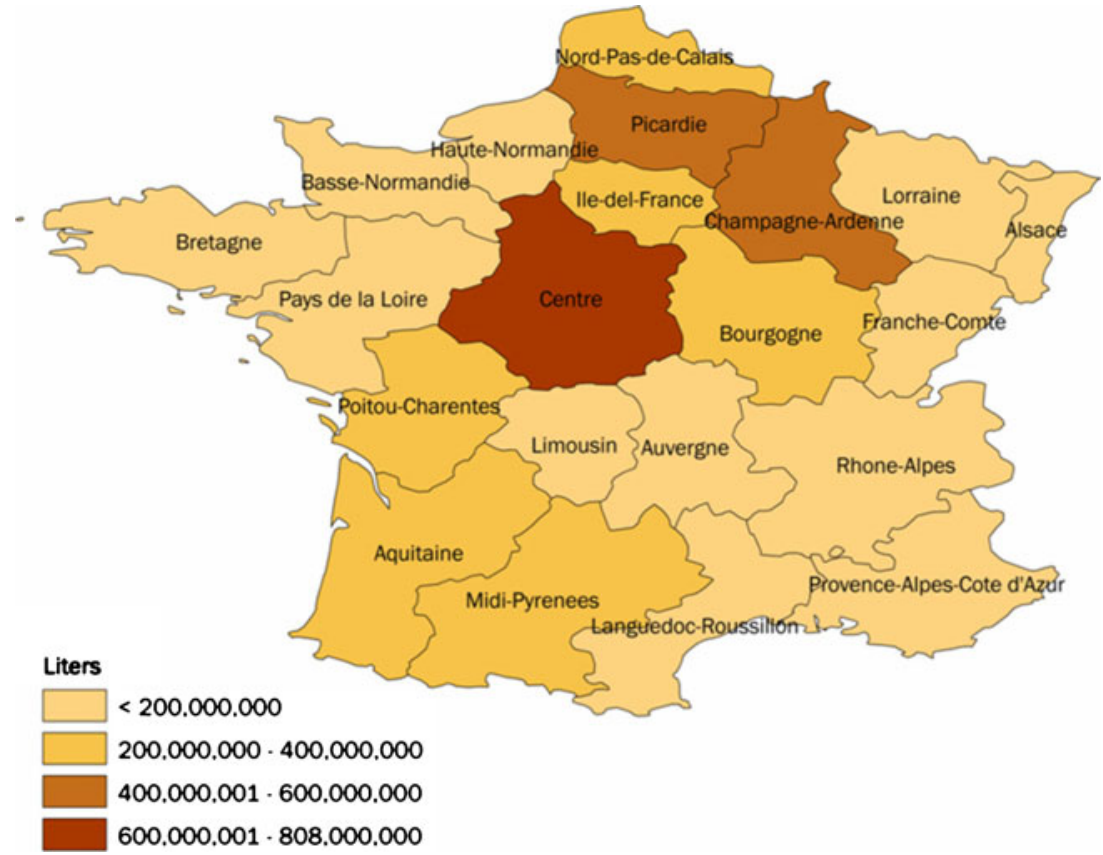


cost is estimated at $0.18 €$ per kilometer per ton (adaptation of the cost estimated for Indiana by Brechbill [5]).

From Romorantin-Lantenay to the border of the region, the average distance is about $150 \mathrm{~km}$. We estimated how far a truck should go to get enough biomass to supply the 200 million liter plant located in Romorantin-Lantenay. As we don't have specific local data, we assumed biomass is evenly distributed for each $\mathrm{km}^{2}$ which gives a biodiesel yield per $\mathrm{km}^{2}$ for each raw material. In region Centre $84 \%$ of the residues are straw and $16 \%$ are corn stover. This proportion is used to estimate the liter per $\mathrm{km}^{2}$ and total production cost. The residue estimation represents the scenario with a removal rate of $35 \%$. The miscanthus production was estimated by the model given the price of $90 € / \mathrm{t} \mathrm{DM}$. The result is miscanthus production of 192,864 ha or $2.4 \%$ of the crop land which correspond at the amount of biomass produced from miscanthus needed to supply 3 plants of 200 million liters. Region Centre produced 26,843 ha (14\% of the miscanthus production). The model results indicate that farmers would not specialize in just the energy crop. However, it is possible that farmers near the biofuel plant would choose to allocate a larger fraction of their crop area to miscanthus. If that happened, then our average miscanthus transportation costs are overestimated. However, the transport cost is a small fraction of the total delivered product cost.

Table 5 contains the results of the three scenarios for supplying a 200 million- liter biodiesel plant. Agricultural residues (scenario1) are the most abundant and cheapest source of biomass compared to growing a specific biofuel feedstock. The production cost per liter of biodiesel is lowest for scenario 1 at $0.35 € / \mathrm{L}$ and highest at $0.61 € / \mathrm{L}$ if the raw material is only miscanthus (scenario 2 ). Therefore, the harvest of agricultural residues is the most financially feasible.

The density of biofuel per square kilometer is the highest in scenario 3 which has a mixed source of biomass (agri- cultural residues and miscanthus). These density results lead to the smallest fuel shed for scenario 3 , but the radius of the fuel shed for scenario 1 is only $4 \mathrm{Km}$ larger. As such, the transportation costs are similar for scenarios 1 and 3 which accounts for the slightly lower cost estimate for agricultural residues (scenario 1).

If only miscanthus were used to supply this plant (scenario 2), the distance over which the biomass would have to be collected $(168 \mathrm{Km})$ is nearly three times the distance for scenario 3 and 8 times the required harvest area in square kilometers. The much larger collection distance combined with the significantly higher production cost is the reason for the much higher cost per liter for miscanthus. In the scenarios considered, the cost of producing miscanthus is too high to compete with producing agricultural residues even if the amount of biomass produced per hectare was higher.

\section{Discussion}

The results showed that the supply of cellulosic biomass from agricultural residues is not uniform across France. However, the regional assessment indicated that nine out of twenty-one regions could potentially build at least one cellulosic plant in 2015. Consequently, this study concludes that France has sufficient biomass to supply at least nine cellulosic plants of 200 million liters of biodiesel by 2015 . Plants in Centre, Picardie and Champagne-Ardenne regions could become economically viable as these regions have large amounts of biomass. Therefore, bigger plants could be considered which would decrease production costs (through economies of scale). These findings should motivate research activities to increase the efficiency of production practices (increased biofuel yield and lower transformation cost) to transform this biomass into biofuel. Ultimately, this also shows that the farmers have the ability to supply

Table 5 Results for a plant supplied with only residues, only miscanthus, or both

\begin{tabular}{llll}
\hline & Scenario 1 & Scenario 2 & Scenario 3 \\
& From agricultural residues & From miscanthus & $\begin{array}{l}\text { From agricultural } \\
\text { residues + Miscanthus }\end{array}$ \\
\hline Cost per Liter $(€ / \mathrm{L}){ }^{\mathrm{a}}$ & & 0.61 & 0.37 \\
Biomass (tons per $\mathrm{Km}^{2}$ ) & 0.35 & 12 & 100 \\
Density (Liter per $\mathrm{Km}^{2}$ ) & 88 & 2,263 & 18,934 \\
Distance From the Plant (radius in Km) & 16,671 & 168 & 58 \\
Production Cost $(€)$ & 62 & $87,912,088$ & $62,176,949$ \\
Transportation Cost $(€)$ & $58,622,337$ & $33,230,769$ & $11,061,659$ \\
Total Cost $(€)$ & $11,772,147$ & $121,142,857$ & $73,238,609$ \\
\hline
\end{tabular}

${ }^{a}$ Assumptions are transportation cost $0.18 €$ per kilometer per ton, production cost of straw: $85 € /$ t, for miscanthus $90 € /$, and for corn stalks $42 € /$ t. 
enough biomass to make a significant contribution to replace the oil used for the nation's fuel needs.

The study also concludes that the amount of biomass available is sensitive to the removal rate ratio. This variability of removal rate is a reality and is found at the farm level. The amount of residues collected in each farm will depend on the land condition. Part of the farms will collect biomass at a removal rate of $25 \%$, the most conservative rate, while others could supply at a higher rate $(35 \%$ or $55 \%)$.

The amount of residues collected will also be influenced by the profitability of biomass harvest for farmers. The residues considered here are by-products, mainly those left in the field after harvesting operations. There is currently no market for corn stover, and there is excess straw from wheat (beyond that currently used for livestock purposes). Thus, the development of a plant in the selected regions should have a positive impact for farmers as it will bring additional income. Guarantee of biomass supply and feedstock prices are important factors to consider for the viability of a plant, so contracts with local farmers would need to be developed. Eventually, the use of straw residues for biomass may compete with other uses such as livestock bedding needs. However, straw quality required for these two markets may be different (lower quality for biomass purpose).

The sustainability of biofuel production is also an important factor to consider for its development. The collection of these residues will produce a new energy source while reducing net emissions of carbon dioxide. However, it may also create additional pressures on soil and water resources. The real long term impact of the harvest of residue is not completely understood. That's why the precise amount of biomass that could be collected remains uncertain. However, most studies indicate that removal of about a third of available residues has minimal impact on soil carbon.

Even if the biomass is available, costs clearly play a key role in the development of the plant. Therefore, we estimated the cost of supplying a plant built in region Centre, the region which has the highest potential. The cost of supplying the plant located in region Centre varies between $0.35 € / \mathrm{L}$ to $0.61 € / \mathrm{L}$ depending on the raw material considered and its abundance. Indeed, to supply a 200 million liter plant of biodiesel, the collection of biomass will be effectively in a circle with a radius of $62 \mathrm{Km}$ to $168 \mathrm{Km}$. The introduction of miscanthus insignificantly affected the distance of collection required to supply the plant. The cost of supplying the plant with miscanthus is much higher than that with residues only as miscanthus production cost is higher than for by-products. Thus, miscanthus production is not economically preferred under the scenarios assessed. This study concludes that crop residues appear to offer a lower cost biomass supply in the near term compared to dedicated crops. However, the high biomass yield of miscanthus and its low input costs could lead to it becoming more attractive, but its production is expected to be limited to certain regions. Miscanthus represents a continuous supply of feedstock with more uniform characteristics that would provide a secure source of supply for a plant. Overall, the development of the second generation biofuel in France will not be limited by the supply of feedstocks but by the cost of transforming biomass into biodiesel. The production of energy crops for biomass will depend on use of land and also the farmer's willingness to introduce a new crop on their farm. This will depend on the existence of long term contracts with cellulosic biomass plants that will guarantee revenue for farmers. The competitiveness with the crop already in production will be limited by the investment required for this new crop. Some current trials are reporting considerably higher miscanthus yields than those used in this analysis. If substantially higher yields $(30+\mathrm{t} / \mathrm{ha})$ could be obtained, dedicated energy crops would become more attractive.

The estimation of potential sources of biomass from current crop production provides grounds for the development of future cellulosic biomass in France without relying too much on the controversial first generation of biofuels. Energy prices and policies toward second generation biofuel will have a significant impact on the amount of biomass produced and collected for second generation biofuel purpose. The possibility of decreasing or abolishing the current aid to the first generation and diverting support to the development of these the second generation biofuel crops will make them economically more viable. Similar incentives, such as long-term contracts before planting for miscanthus or subsidies such as ACE ("Aide aux Cultures Energétiques") available for the first generation biofuels crops could be considered. As competition for biomass resources rise, the use of both dedicated energy crops and residues could be promoted in order to meet the increasing demands. A mix of first and second generation biofuel crops can be expected in 2015 .

\section{References}

1. Agreste (2008). Agreste Conjoncture, grandes cultures, Synthèses, 2008/16 http://agreste.agriculture.gouv.fr/IMG/pdf/synthesecultures 0804.pdf . Cited 10 Oct 08

2. Bamière L, Bureau JC, Guindé L, Guyomard H, Jacquet F, Treguer D (2007) Prospects for EU Biofuel Production and Trade, Working paper, December 2007

3. Bernard F, Prieur A (2007) Biofuel market and carbon modelling to analyse French biofuel policy. Energy Policy 35:5991-6002

4. Bical Biomasse France (2007). Information sur la culture du miscanthus Personnal communication 
5. Brechbill S (2008) The economics of biomass collection and transportation and its supply to indiana cellulosic and electric utility facilities. Master Thesis, Purdue University

6. Bullard M (2000) NF0403- Miscanthus Agronomy (for fuel and Industrial uses). Ministry of Agriculture, Fisheries and Food Scientific (MAFF) Report no.NF0403. London: MAFF, 2000

7. Clifton-Brown JC, Lewandowski I, Andersson B, Basche G, Christian DG et al (2001) Performance of 15 miscanthus genotypes at five sites in Europe. Agron J 93:1013-1019

8. Commission of the European communities (2007) Communication from the commission to the council and the European parliament

9. Department for Environment Food \& Rural Affairs (DEFRA) (2007) Planting and growing miscanthus: Best practice guidelines. England. http://www.defra.gov.uk/erdp/pdfs/ecs/miscanthusguide.pdf $9 / 10 / 08$

10. Douaud A, Gruson JF (2006) Recommandations pour un développement durable des Biocarburants en France. Co

11. Dronne Y, Gohin A (2007) Biocarburants et marchés internationaux des matières premières agricoles. Chambre de commerce et d'industrie de Paris ACCOMEX 76:9-13

12. EC Baltic Renewable Energy Centre (EC-BREC) (2008) Energy crops potential inventory-Country profiles, $38 \mathrm{http} / / / \mathrm{www} \cdot$ renewfuel.com/fs_documents.php 9/10/08

13. Ericsson K, Nilsson LJ (2006) Assessment of the potential biomass supply in europe using a resource-focused approach. Biomass Bioenergy 30(1):1-15

14. Europa (2007) The Kyoto protocol http://ec.europa.eu/environment/ climat/gge.htm. Cited 20 June 08

15. Europa (2008) FADN http://ec.europa.eu/agriculture/rica/ index_en.cfm. Cited 20 August 08

16. Gabrielle B, Gagnaire N (2008) Life-cycle assessment of straw use in bio-ethanol production: a case study based on biophysical modelling. Biomass Bioenergy 32(5):431-441

17. Gagnaire N, Gabrielle B, Da Silveira JC, Sourie JC, Bamiere L (2006) Une approche économique, énergétique et environnementale du gisement et de la collecte des pailles et d'une utilisation pour les filières éthanol. http://www.grignon.inra.fr/ economie publique/pages publication/SOURIE.html. Cited 17 June 08

18. GIE Arvalis/Onidol (2008) Project ECOBIOM, financed by ANR, personnal communication

19. Guindé L, Jacquet F, Millet G (2007) Les biocarburants et l'agriculture française : une simulation des impacts de la directive européenne sur la production française de grandes cultures. Journées INRA-SFER de recherche en sciences sociales; 2007/ 12/13-14; Paris. 17

20. Guindé L, Millet G, Bamière L, Jacquet F (2007) Analyse de l'impact d'une nouvelle réforme de la PAC et d'une politique de développement des biocarburants sur les exploitations de grandes cultures. http://www.prodinra.inra.fr/prodinra/pinra/data/ 2007/11/PROD200768df5053_20071119034430847.pdf. Cited 06 May 08

21. Heaton EA, Clifton-Brown JC, Voigt TB, Jones MB, Long S (2004) Miscanthus for renewable energy generation: european union experience and projections for Illinois. Mitig Adapt Strategies Glob Chang 9:433-451

22. Hill J, Nelson E, Timan D, Polasky S, Tiffany D (2006) Environmental, economic, and energetic costs and benefits of biodiesel and ethanol biofuels. Proc Natl Acad Sci USA 103 (30):11206-11210

23. Hoogwijk M, Faaij A, Van den Broek R, Berndes G, Gielen D, Turkenburg W (2003) Exploration of the ranges of the global potential of biomass for energy. Biomass Bioenergy 25: 119-133
24. Huisman W, Molenaar J, Venturi P (1998) Mechanization and Costs of Primary Production Chains for Miscanthus X Giganteus in the Netherlands. J Agric Eng Res 69:209-215

25. IFP (2007), Panaorama 2007: 1-6 www.ifp.com/content/download/ 56045/1266567/version/6/file/IFP-Panorama07_07-Potentiel biomasse_VA.pdf Cited 12 May 08

26. Institut national de la statistique et des études économiques (Insee) (2009) http://www.insee.fr/fr/themes/theme.asp?theme $=10 \&$ nivgeo $=18$ Cited 14 May 08

27. Ivanic R (2008) Personal communication

28. Khanna M, Dhungana B, Clifton-Brown J (2008) Costs of producing miscanthus and switchgrass for bioenergy in Illinois. Biomass Bioenergy 32:482-493

29. Kim S, Dale BE (2004) Global potential bioethanol production from wasted crops and crop residues. Biomass Bioenergy 26(4):361-375

30. Koopmans A, Koppejan J (1997) Agricultural and forest residues generation, utilization and availability. Paper presented at the Regional Consultation on Modern Applications of Biomass Energy, 6-10 January 1997, Kuala Lumpur, Malaysia

31. Lal R (2005) World crop residues production and implications of its use as a biofuel. Environ Int 31:575-584

32. Leplus A, Merle S (2007) Quelles cultures pour quels usages?. Entraid' : 2-4. http://www.aile.asso.fr/valorisation-de-la-biomasse/ culturesenergetiques/quelles-cultures-pour-quels-usages-dossier/ safirbiomasse-3p.pdf Cited 6 May 08

33. Lewandoski I, Clifton-Brown JC, Scurlock JMO, Huisman W (2000) Miscanthus: European experience with a novel energy crop. Biomass Bioenergy 19:209-227

34. Marsac S (2007) Présentation des enjeux de production d'une culture dédiée à la production d'une culture dédiée à la production d'énergie en agriculture. Colloque «Quelle biomasse pour produire de l'énergie de demain ? ", SIMA, 07/03/07

35. Moiser N (2006) Cellulosic ethanol-biofuel beyond corn (ID-335), Purdue University Cooperative Extension Service

36. Nelson R (2002) Resource assessment and removal analysis for corn stover and wheat straw in the Eastern and Midwestern United States_Rainfall and wind-induced soil erosion methodology. Biomass Bioenergy 22:349-363

37. Office National Interprofessionnel des Grandes Cultures (ONIG) (2007) Biocarburants 2010: Quelles utilisations des terres en France?. http://www.onigc.fr/pdf/FR/bio1107.pdf Cited 22 June 08

38. Perlack RD, Wright LL, Turhollow AF, Graham RL, Stokes BJ, Erbach DC (2005) Biomass as feedstock for a bioenergy and bioproducts industry: the technical feasibility of a billion-ton annual supply, DOE/GO-102005-2135, Oak Ridge National Laboratory, Oak Ridge, Tennessee http://feedstockreview.ornl. gov/pdf/billion_ton_vision.pdf Cited 10 October 08

39. Protin PV (2007) Cultiver la biomasse en préservant la qualité des sols. Colloque «Quelle biomasse pour produire de l'énergie de demain ?», SIMA, 07/03/07

40. RFA (2007) Industry Statistics.Retrieved July 4, 2008, from http:// www.ethanolrfa.org/industry/statistics/\#E06/20/08

41. Rozakis S, Sourie JC (2005) Micro-economic modeling of biofuels system in france to determine tax exemption policy under uncertainty. Energy Policy 33:171-182

42. Rozakis S, Sourie JC, Vanderpooten D (2001) Integrated microeconomic modeling and multicriteria methodology to support public decision-making: the case of liquid bio-fuels in France. Biomass Bioenergy 20:385-398

43. Sanderson M, Adler P (2008) Perennial forages as second generation bioenergy crops. Int J Mol Sci 9:768-788

44. Stumborg P, Townley-Smith (2004) Agricultural Biomass Resources in Canada. ASAE/CSAE Meeting Presentation http://asae.frymulti.com/ azdez.asp?JID $=5 \& \mathrm{AID}=17048 \& \mathrm{CID}=$ can2004\&T=2 Cited 2 Oct 08 
45. Thivolle-Cazat A, Jacquin C, Graffin A, Pitocchi S (2007) Une Approche Soci-Economique et Environnementale de l'Offre de Biomasse Ligno-cellulosique. ECOBIOM-Phase 10-livrable 2définition des bassins d'approvisionnement

46. Tréguer D, Sourie JC (2006) The impact of biofuel production on farm jobs and income. The French case. Laboratoire d'Economie Publique INRA and INA P-G, Grignon

47. Tyner W, Caffe M (2007) US and French biofuels policypossibilities for the future, Paper presented at the OECD Workshop on Bioenergy Policy Analysis, Umea, Sweden, 22-23 January 2007
48. Vanderdriessche V (2007) Etude des facteurs de rendement d'une espèce dédiée aux bioénergies: découverte des déterminants agronomiques de miscanthus $\mathrm{X}$ giganteus. Etude des Essais de Grignon et Lusignan. Mémoire de fin d'étude

49. Warnant G (2007) Miscanthus : aspect culturaux. 4èmes rencontres de la biomasse, Quelles Ressources pour les Biocombustibles de Demain. Valbiom, Gembloux

50. Wright M, Brown R (2007) Comparative Economics of Biorefineries based on the Biochemical and Thermochemical Platforms. Biofuels, Bioproducts, and Biorefining 1:49-56 